\title{
EL COOPERATIVISMO DE AYUDA MUTUA EN EL URUGUAY: UNA ALTERNATIVA POPULAR Y AUTOGESTIONARIA DE SOLUCION AL PROBLEMA DE LA VIVIENDA
}

\author{
(MUTUAL ASSISTANCE COOPERATIVISM IN URUGUAY: A SELF-ADMINISTRATING \\ PEOPLE'S ALTERNATIVE FOR SOLVING THE HOUSING PROBLEM)
}

\author{
Benjamin Nahoum \\ Centro Cooperativista Uruguayo \\ URUGUAY
}

\section{RESUMEN}

El presente trabajo procura describir las características del sistema de construcción de viviendas por Cooperativas de Ayuda Mutua, implantado en el Uruguay, en 1968. Se analizan sus ventajas respecto de otros sistemas en países de economía capitalista dependiente en aspectos económicos, urbanísticos, en la adaptación a las necesidades de los destinatarios $y$, sobre todo, en lo referente al profundo sentido social y comunitario que estas experiencias contienen.

Este aspecto, que reafirma valores solidarios arraigados en los sectores populares organizados en las Cooperativas, conduce posteriormente a los grupos a encarar, también colectivamente, otros problemas sociales que ellos enfrentan, emergentes de las condiciones de subdesarrollo y dependencia de los países latinoamericanos; éste es, en definitiva, más allá de la indiscutible validez, el cooperativismo de vivienda como solución a la problemática habitacional, el rasgo sustantivo de este tipo de experiencias.

\section{SUMMARY}

This work attempts to describe the characteristics of the system of building houses by Mutual Assistance Cooperatives, which was introduced in Uruguay in 1968. Its advantages are analyzed with respect to other systems in countries with a capitalist economy, dependent in economic and urban aspects on adapting to the needs of those it is designed for and, in particular, with reference to the profound social and community meaning contained in these experiments.

This aspect, which reaffirms values of solidarity deeply-rooted in the sectors of society organized into Cooperatives, subsequently leads the groups to also face colectively other social problems they come up against, which arise from the conditions of under-development and dependence pertaining to Latin American countries: in short, the substantive feature of this type of experience, more than its unquestionable validity, is rather the idea of housing cooperativism as a solution to the habitation problem.

\section{Introducción}

La construcción de viviendas por el sistema de Cooperativas de Ayuda Mutua se implanta en el Uruguay, luego de una experiencia piloto con tres grupos del interior del país Ilevada a cabo por el Centro Cooperativista Uruguayo, al incluirse este sistema en la Ley Nacional de Vivienda votada por el Parlamento Nacional en 1968. Superadas las dificultades iniciales propias de una modalidad que era prácticamente inédita en el país (y superada incluso de desconfianza que los propios interesados tenían al comienzo respecto a ella), en 1975 uno de cada dos préstamos que se solicitaban ante el Banco Hipotecario del Uruguay para la construcción de una vivienda correspondían al régimen cooperativo, ya sea en su modalidad de Ayuda Mutua o en la de Ahorro Previo. En particular el sistema de Cooperativas de Ayuda Mutua probaba a esa altura que era el más idóneo para recoger, organizándola, toda una tradición de miles de autoconstructores que en la primera mitad del siglo fueron los que dieron un decisivo impulso de crecimiento a las ciudades uruguayas.

Pero las Cooperativas de Ayuda Mutua fueron todavía más que eso: a quince años de vigencia de la Ley Nacional de Viviendas, el sistema cooperativo surge como aquél que ha permitido obtener mejores so- luciones a más bajo costo, el que ha dado resultados más positivos respecto de la conservación, mantenimiento y complementación urbana de los conjuntos, el que se ha ajustado mejor a las necesidades de los destinatarios, el que ha producido una más plena valoración y utilización de los espacios comunitarios. Por otra parte, la organización adquirida por los grupos durante la etapa de obra (que se prolonga posteriormente, porque el sistema de propiedad colectiva por el que la casi unanimidad de ellas ha optado requiere la permanencia de estructuras de uso y administración del bien común), ha llevado naturalmente a encarar, también en forma colectiva, otros problemas sociales comunes: así han surgido policlínicas, guarderías, bibliotecas, cooperativas de consumo, que han contribuido a mejorar la calidad de vida de los cooperativistas, pero también las de la comunidad circundante a la que las Cooperativas están abiertas. La extracción obrera de la gran mayoría de los integrantes de los grupos ha sido, además, un poderoso factor de organización, de disciplina y de concienciación, que convirtió a las Cooperativas de Vivienda en un importante baluarte de la lucha por la recuperación de la democracia en el uruguay. Este mismo hecho trajo como consecuencia que de 1975 en adelante el apoyo oficial a este sistema fuera prácticamente nulo; antes bien, desde los organismos rectores de la política de vivienda se implementaron medidas que golpearon dura- 
mente al Cooperativismo. Hoy, a las puertas de una redemocratización que todo el país anhela, las Cooperativas de Vivienda esperan ocupar, cuando llegue ese momento, el lugar que les corresponde déntro de las políticas habitacionales del Uruguay, al tiempo que algunas experiencias que se inician en otros países de la región, tomando como referencia el sistema uruguayo, permiten pensar además que el mismo, con las adaptaciones necesarias a cada realidad local, puede constituir una auténtica alternativa popular al problema de la vivienda en Latinoamérica.

\section{Del esfuerzo propio a la ayuda mutua}

La mayoría de las ciudades uruguayas, y particularmente la capital, Montevideo, (que concentra casi la mitad de la población del país), han crecido al influjo de la autoconstrucción, como es habitual en Latinoamérica. Pero lo peculiar de ese proceso, en el caso uruguayo, es que el mismo no ha sido explosivo, como en otros países de la región, sino que por el contrario ese crecimiento se produjo de manera gradual, a favor de la prosperidad económica relativa que se dio en el país hasta la década del 60 , del reducido crecimiento demográfico, y de una legislación que abrió canales de crédito e instrumentó, a través de mecanismos como el "Plano de Vivienda Popular" (que las Intendencias entregaban gratuitamente a los interesados), la construcción de la casa propia por parte de las capas medias y de buena parte de los sectores asalariados urbanos. Es así que el parque de viviendas en los núcleos poblados se cuadruplica entre 1920 y 1960 (1), en tanto la población sólo se duplicaba.

Un país de autoconstructores, entonces. De gente dispuesta a construir su vivienda con sus propias manos, contando apenas con el auxilio de algún familiar o amigo y del apoyo que podría darle un albañil o constructor en las etapas más difíciles, aquellas que exigen el conocimiento del trabajador especializado: el techo, casi siempre una losa de hormigón, las instalaciones eléctrica y sanitaria, y casi nada más.

Y es que este país aluvional, edificado por las sucesivas generaciones de inmigrantes que vinieron a poblarlo, españoles e italianos fundamentalmente, es un país donde abundan los "siete oficios", las personas que saben un poco de todo, o que han debido aprenderlo para abrirse camino en la sociedad que venían a conquistar.

No es de extrañar entonces que esos hombres y esas mujeres no se amedrentarán ante la empresa de construir su techo basándose en su propias fuerzas, a partir de un terrenito en los suburbios comprado en pequeñas cuotas en aquellos lotes masivos que los especuladores inmobiliarios realizaran en las primeras décadas del siglo.

Pero la situación económica del país cambia fundamentalmente luego de la.segunda posguerra y sobre todo a partir de la finalización de la guerra de Corea, que extiende por algunos años más las relaciones favorables de precios de los productos que el Uruguay exporta. Así se pasa de porcentajes de inflación anual por debajo del $20 \%$, a más del $50 \%$ a partir de 1965 , con un pico del $136 \%$-récord en toda la historia del país - en 1967; el precio del dólar en el mercado financiero, que era de poco más de $\$ 3$ en 1955 pasa a \$ 11 en 1962, \$ 128 en 1967 y $\$ 249$ en 1968; el salario real, en fin, cae un $20 \%$ entre 1957 y 1966 (2). El deterioro económico que reflejan estas cifras, que repercute antes que nada en la situación de los trabajadores, es el que lleva a que se produzca una grave crisis en la construcción de viviendas, que se refleja en varios hechos muy importantes: los metros cuadrados construidos por año caen de más de un millón y medio en 1956 a la mitad en 1963; la inversión en viviendas en relación al PBI cae un 50 \% en el mismo lapso; los préstamos escriturados por el Banco Hipotecaria del Uruguay, organismo financiador de la vivienda, pasan de una cifra del orden de los 10.000 millones de pesos en el período 1955-1958 a sólo 350 millones en 1968 (3).

La crisis golpea a la construcción toda, pero particularmente a la legión de autoconstructores, a los que resultará imposible en adelante intentar solos la aventura de levantar su techo. Ahora será necesario unir esos esfuerzos aislados para obtener economías de costos, para hacer más eficaces los esfuerzos, para poder enfrentar mejor los compromisos de devolución de los créditos. Una nueva forma organizativa está llamada a aparecer, entonces, para recoger aquella tradición, implementándola y haciéndola más eficiente: las Cooperativas de vivienda por Ayuda Mutua. Ella recogerá por un lado, la experiencia de los autoconstructores, y por otro, la de las organizaciones populares de rica historia en el país, particularmente las de los sindicatos de trabajadores.

\section{De 95 familias a $\mathbf{1 0 . 0 0 0}$}

La nueva organización implica la simbiosis de una forma organizativa, la Cooperativa, y una forma de trabajo, la construcción por ayuda mutua.

Cooperativa en primer lugar, o sea una organización de iguales, dirigida democráticamente por su base social a través de los órganos de dirección y control que la misma constituye $y$ designa. $Y$ cooperativa de Vivienda, es decir una asociación de familias que frente a la necesidad común de vivienda aportan el esfuerzo y la iniciativa de todos sus miembros para solucionarla en forma conjunta.

Cooperativa de ayuda mutua, por fin, lo que quiere decir que uno de sus recursos centrales para la consecución de sus objetivos será el aporte de mano de obra de las familias que la integran.

Las primeras experiencias en este sentido serán tres proyectos piloto surgidos en 1966 en el interior del país, con la promoción del Centro Cooperativista Uruguayo. En ese año tres grupos de trabajadores, en 
Salto, Fray Bentos e Isla Mala, deciden constituirse en Cooperativas para satisfacer sus necesidades de habitación. Son en total 95 familias, que formarán tres Cooperativas de Consumo (no existía la forma jurídica Cooperativa de Vivienda) y con ello marcarán el hito fundamental a una experiencia que habrá de crecer vertiginosamente y multiplicarse por 100 en menos de una década. Tropiezos y dificultades de todo tipo jalonan el camino de estos grupos, que estaban construyendo sus viviendas y simultáneamente una forma de organización en la que todo estaba por inventar. El balance general resultó muy positivo, sin embargo, al punto que un documento oficial de la época señala que "de todos los conjuntos habitacionales realizados en el país en el año 1969, sea por organismos públicos o empresas privadas, las inversiones necesarias y por tanto, las cuotas de amortización más bajas, han sido obtenidas por estas cooperativas". Los años siguientes mostrarán que los resultados en cuanto a la satisfacción de las necesidades habitacionales y en cuanto a las formas de convivencia serían igualmente positivos. Es por ello que cuando en diciembre de 1968 el Parlamento vota una Ley de Viviendas destinada a atacar los problemas jurídicos, económicos y organizativos que habían conducido a un déficit de más del $10 \%$ del parque existente, esa Ley preverá que una de las formas de construcción de nuevas viviendas será a través de las Cooperativas de Ayuda Mutua.

Claro que no era éste el sistema que servía a los grupos de empresarios que habían presionado para que esta Ley fuera votada, y que la habían impulsado a través de sus representantes en las Cámaras. Estos sectores propulsaban las construcciones de viviendas por el régimen de "Promoción Privada", en que el Estado proporciona créditos a inversores privados para construir viviendas que luego serán vendidas en el mercado, o por el "Sistema Público", que implica la construcción por empresas privadas de proyectos administrados por el Estado. Para propiciar estos sistemas, para regular las inversiones y proveer los recursos necesarios, para poner en marcha, en fin, el vasto plan de construcciones que las empresas requerían, luego de una década de crisis de esa industria, es que se vota la Ley. Dentro de esa estrategia, el sistema cooperativo aparece como un capítulo marginal, integrado a la Ley más para facilitar su tránsito parlamentario que para apoyar verdaderamente en él un intento serio de solucionar los problemas habitacionales. No será ésta, sin embargo, la visión de los interesados. Superada una primera etapa de escepticismo y desconfianza hacia una alternativa que parecía utópica, superadas también las dificultades de la puesta en marcha a nivel masivo de una experiencia que sólo conocía antecedentes puntuales, y en la que era preciso montar todo el andamiaje administrativo y reglamentario del que carecía, el cooperativismo hace eclosión y toma rápidamente el primer lugar en las preferencias de la población entre todos los sistemas que la Ley preveía para acceder a la vivienda. Así, en 1975 uno de cada dos créditos solicitados en el Banco Hipotecario, correspondían al sistema cooperativo. Dentro de éste, las Cooperativas de Ayuda Mutua eran, a su vez, más de las dos terceras partes. (El resto correspondía a Cooperativas de Ahorro
Previo, sistema en que el aporte de los destinatarios se hace por ese mecanismo en lugar de efectuarlo a través del trabajo en la obra). Será el punto más alto, y al mismo tiempo el comienzo de un descenso vertiginoso, originado por cierto no en problemas del sistema, ni en la falta de apoyo de la población, sino en expresas decisiones políticas.

Producido el golpe de Estado de 1973 en el Uruguay, implantado el neoliberalismo económico al año siguiente, las Cooperativas de Vivienda aparecen como una doble contradicción dentro del sistema: por su contenido participativo y democrático cuestionan el autoritarismo que pasa a ser el estilo de gobierno imperante; por su contenido de autogestión económica, chocan con el nuevo modelo, que basa su acción en la intervención de las empresas capitalistas, a las que busca estimular a través de mayores rentabilidades.

Esa doble contradicción es prontamente advertida, y las consecuencias son el retiro de todo tipo de apoyo al cooperativismo, y muchas veces, incluso, el ataque directo: desde 1976 no se conceden personalidades a Cooperativas de Ayuda Mutua, lo que significa que no se han podido formar nuevos grupos; de 1975 a 1977 estuvieron interrumpidos los préstamos (para la mayoría de los grupos hasta 1979), lo que llevó a la desarticulación de muchas de las numerosas Cooperativas que se habian constituido; se endurecieron sensiblemente las condiciones de crédito, aumentándose los intereses, que hoy son el triple de los vigentes a 1975, e imponiéndose la exigencia de un ahorro previo, que es incompatible con un sistema que apunta a sectores sin capacidad de ahorro; los trámites se alargaron, además, sensiblemente, colocándose trabas burocráticas de todo tipo. $Y$ esto solamente en lo que se refiere a problemas específicos, puesto que a ello hay que sumar, naturalmente, las dificultades por las que han atravesado ( $y$ atraviesan) en este período, todas las organizaciones democráticas del país: partidos políticos, sindicatos, asociaciones estudiantiles, etc.: dificultades para reunirse, para expresarse, para actuar, persecución a sus dirigentes; la falta de libertad para decirlo con una sola frase. Y esto en un marco de grave crisis económica, cuyos costos han pagado los sectores de trabajadores, que han visto reducirse su salario real a la mitad en menos de una década.

La consecuencia de todo esto ha sido que el cooperativismo se destina hoy apenas el $3 \%$ de las inversiones en vivienda del país, y que no puede acceder a él el $40 \%$ de ingresos más bajos de la población, aquél para el que naturalmente está destinado. Este hecho, que depende como hemos dicho de resoluciones políticas, será revertido por otras resoluciones políticas de signo opuesto, por las que hoy todo el pueblo uruguayo lucha. Pero eso es otra historia.

\section{Solidaridad, organización, autogestión}

¿Cómo funciona una Cooperativa de Ayuda Mutua? Ante todo, la Cooperativa es una empresa - una empresa cooperativa- cuyo objetivo inicial es la 


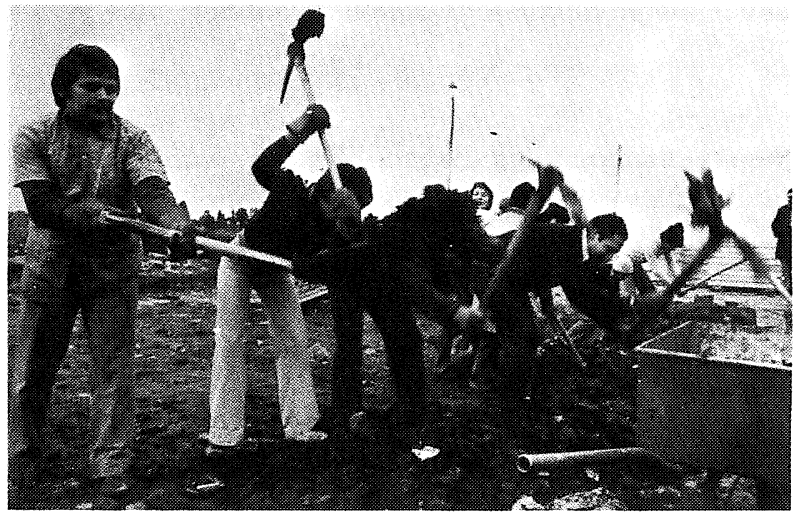

Fig. 1. - Se empieza abriendo zanjas. Luego habrá que aprender a hormigonar. preparar armaduras, prefabricar elementos y pintar. A veces se llega hasta a hacer la carpintería y herrería de obra.

construcción de las viviendas para sus socios. $Y$ decimos inicial porque luego veremos que la cosa no termina ahí, casi nunca.

Los recursos que la empresa cooperativa necesita para cumplir ese objetivo económico provienen de dos fuentes fundamentales: los créditos que se le otorgan de acuerdo a la Ley de Viviendas, por un lado y el aporte de mano de obra de los integrantes del grupo por otro. Esos recursos son administrados por los propios asociados, que se organizan a ese efecto, y cuentan para ello con el asesoramiento técnico de equipos pro- fesionales interdisciplinarios, sin fines de lucro, cuya actuación está prevista y regulada por la propia Ley. No hay por consiguiente, intermediario alguno que procure lucro. Esta es una primera condición esencial.

Una segunda condición es la contribución de los propios destinatarios, con su esfuerzo, a la solución del problema. Dado que por tratarse de sectores de bajos ingresos, esa contribución no puede hacerse más que con trabajo, el aporte se realiza a través de la ayuda mutua y de las tareas de gestión de la cooperativa (que en definitiva son otra forma, más especializada, de ayuda mutua). Sintéticamente podríamos decir que la ayuda mutua es la ejecución de las obras mediante el aporte de mano de obra de los interesados trabajando colectivamente y empleándose mano de obra contratada únicamente en los casos en que ello es estrictamente necesario por razones de organización o de especialización de la tarea (Figs. 1 y 2). Ese aporte de ayuda mutua es controlada por un reglamento que la propia Cooperativa aprueba en Asamblea; durante las obras es en general de 20 a 25 horas por núcleo familiar, de las cuales hay un porcentaje que debe ser realizado por hombres adultos integrantes del mismo. Surge de lo dicho que la construcción se basa en la mano de obra de ayuda mutua: ello obliga a usar tipologías y sistemas constructivos apropiados, que permitan obtener el máximo rendimiento de un aporte de mano de obra en principio no especializado, y con el
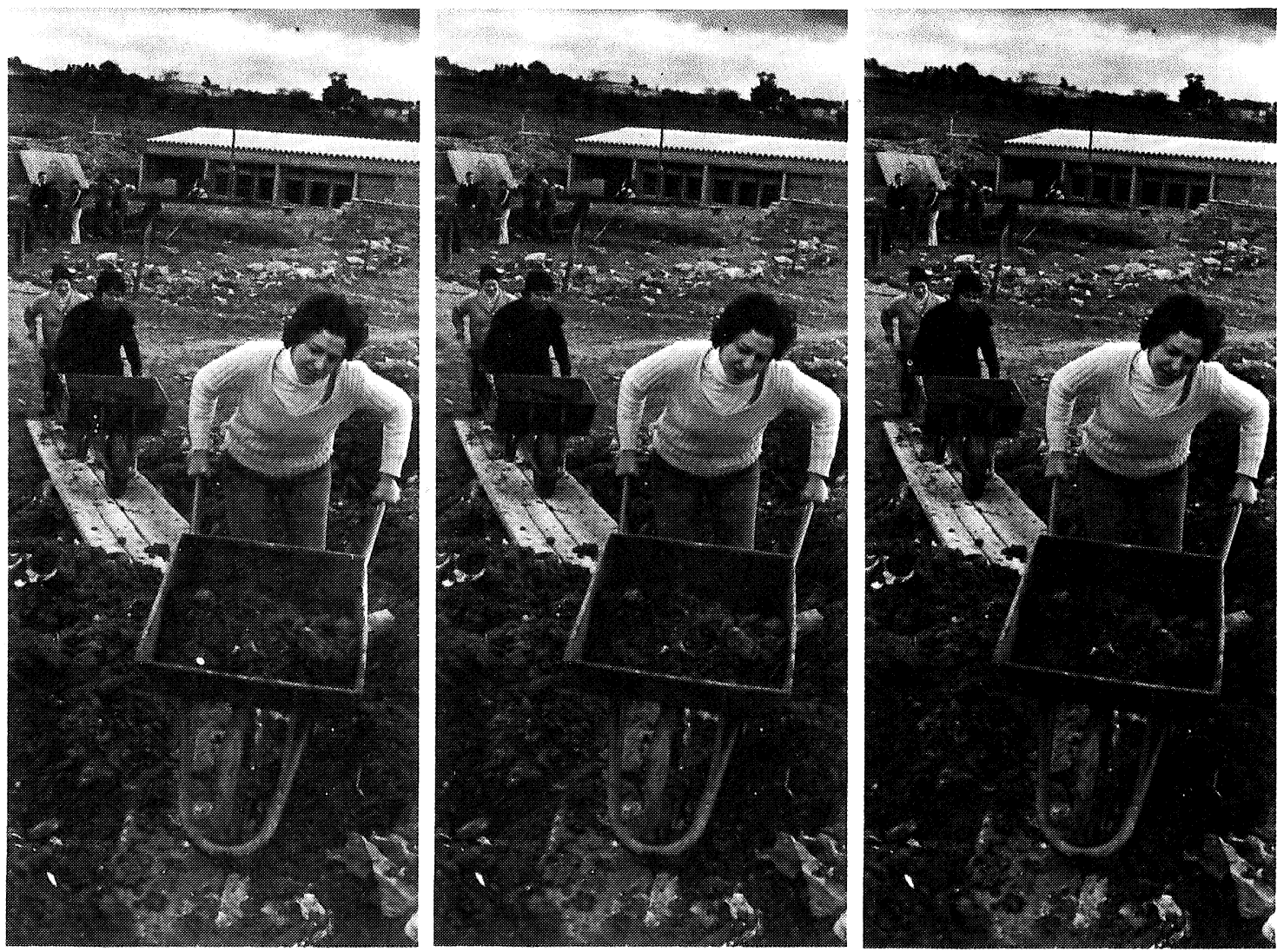

Fig. 2. - La mujer también tiene un papel en la obra. Su trabajo se vuelca generalmente a las tareas que requieren mayor prolıidad y esmero, pero si hay que acarrear tierra, también está presente. 
Informes de la Construcción. Vol. $36, n{ }^{\circ} 362$, julio, 1984

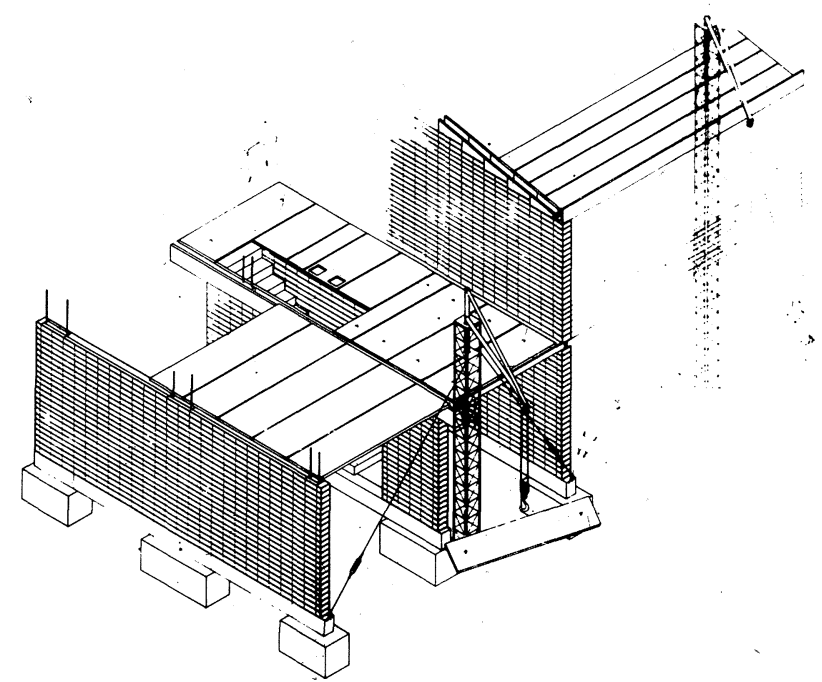

Fig. 3. - Sistema constructivo usado en varios conjuntos de Montevideo: entrepisos y techos de losetas pretensadas de hormigón, apoyadas en muros portantes de cerámica.

uso de un equipamiento que sea amortizable en lo posible en una sola obra (Fig. 3).

Es así que se ha llegado a construir hasta cuatro niveles de altura, pero preferentemente se han realizado viviendas de uno y dos niveles.

Por otra parte, se ha utilizado en general un sistema constructivo en el que se combina la construcción "tradicional" racionalizada con el empleo de elementos prefabricados como losetas para entrepisos y techos, y con la simplificación de las terminaciones. La prefabricación de algunos elementos cumple un cometido muy importante, porque permite:

- Simplificar tareas, haciendo posible que sean realizadas por mano de obra no especializada, incluida la femenina.

- Realizar tareas independientemente de la coordinación con el trabajo del personal contratado.

- Un mejor control de calidad al concentrarse las tareas en un lugar en vez de realizarse en distintos puntos de obras muy extendidas.

Otro aspecto de gran importancia para el logro de los objetivos económicos de la cooperativa es el funcionamiento adecuado de la autogestión y su fluida relación con el asesoramiento técnico. La autogestión, o sea la toma de las decisiones que hacen a la marcha de la Cooperativa y en particular de la obra por los órganos competentes del propio grupo, resulta posible en la medida que éste tenga capacidad de actuar con independencia y en forma democrática en esa toma de decisiones. $Y$ esto quiere decir que el grupo podrá recibir todas las formas de asesoramiento técnico que sean necesarias pero en definitiva debe estar en condiciones de que la resolución final sobre cada tema pertenezca a la propia cooperativa actuando en forma democrática.' Si esto se logra, no sólo se llega a los mejores resultados en cuanto a la obra, sino que se consigue instrumentar una capacidad organizativa en el grupo que le permite luego expandir su acción a otros campos, permitiéndole enfrentar problemas y tomar decisiones en áreas diversas, que ni siquiera imaginaban al comenzar el trabajo.

El cooperativismo de vivienda por ayuda mutua se basa, pues, en la organización del esfuerzo solidario de familias que enfrentan un problema común, para resolverlo con su propia acción y por autogestión. Es, entonces, una forma de enfocar la solución al problema de la vivienda que implica: la utilización de los recursos disponibles de la población: su capacidad de organización, de administración, y de aporte de mano de obra para la construcción, mejoramiento y conservación de los conjuntos habitacionales; el apoyo del Estado para resolver los temas de: tierras, infraestructura, créditos y subsidios; en fin, una forma de trabajo de los técnicos, en equipos multidisciplinarios, y en relación con los usuarios.

\section{Cómo funciona una cooperativa de ayuda mutua}

De acuerdo a la Ley Nacional de Viviendas y sus reglamentaciones, las Cooperativas tienen cinco órganos de dirección y control: la Asamblea General, el Consejo Directivo, la Comisión Fomento, la Comisión Fiscal y la Comisión Electoral.

- La Asamblea General, en que cada familia socia tiene un voto, es el órgano máximo, depositario de la soberanía del grupo. Ella tiene competencia sobre todos los aspectos que hacen a la vida de la Cooperativa. En particular. considerar y aprobar la Memoria Anual, establecer la integración del capital social y de los fondos especiales, modificar el número de integrantes de los órganos de dirección y elegir a sus integrantes, así como entender en la marcha de las obras (asambleas ordinarias); reformar los estatutos, disolver la Cooperativa o decidir su fusión con otras o la integración a organizaciones de segundo grado (asambleas extraordinarias).

La Asamblea puede ser convocada por el Consejo Directivo, por la Comisión Fiscal o por los socios, en este caso con el $10 \%$ de las firmas conformes.

- El Consejo Directivo es el órgano de representación dirección y ejecución de la Cooperativa. En general está integrado por cinco o siete miembros, electos por la Asamblea, que se distribuyen las funciones de Presidente, Secretario y Tesorero, así como las tareas que competen al órgano. Durante la etapa de la construcción el Consejo Directivo es el que tomas las decisiones referentes a la administración de las obras, dando cuenta de sus actuaciones a la Asamblea General a través de informes generalmente mensuales. Esas decisiones incluyen la utilización de los recursos financieros (préstamo del Banco Hipotecario), compra y control de materiales, equipo y herramientas, contratación y control de la mano de obra necesaria, trámites ante el Banco Hipotecario y otros organismos 

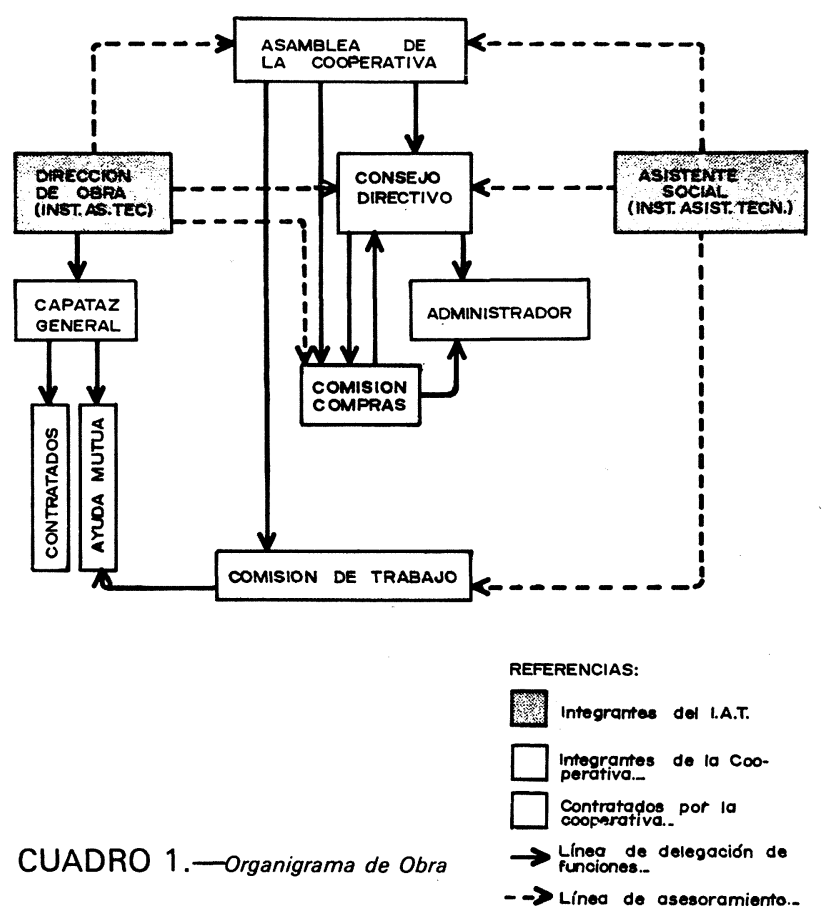

CUADRO 1.-Organigrama de Obra $\rightarrow$ Línea de asesoramiento.

públicos, etc. En esta etapa el Consejo Directivo cuenta con el apoyo de dos sub-comisiones que colaboran con él: la de Trabajo y la de Obras; en ésta participan además, el Capataz y el administrador (funcionarios rentados de la Cooperativa) y el Arquitecto Director de Obra, que integra el Instituto de Asistencia Técnica. Esta sub-comisión es la responsable de la organización y realización de la obra, en tanto la sub-comisión de Trabajo tiene por función, a su vez, organizar y controlar el cumplimiento de la Ayuda Mutua por parte de los socios (ver organización de obra en Cuadro N. $\left.{ }^{0} 1\right)$.

- La Comisión Fomento es el órgano de la Cooperativa que se encarga de la información, comunicación e integración del socio y su familia al grupo, así como de la relación de la Cooperativa con la comunidad.

- La Comisión Fiscal es el órgano de control de la Cooperativa. Esta función abarca los aspectos financieros y de administración, así como también el cumplimiento de los fines de la Cooperativa.

- La Comisión Electoral, finalmente, se ocupa de todo lo que tiene que ver con la elección de autoridades de la Cooperativa (preparación del acto electoral, control del mismo, escrutinio, proclamaciones, atender y. decidir en las reclamaciones que se formulen, etc.).

Este conjunto de funciones, sin duda complejo, que los cooperativistas deben asumir en la Asamblea General o a través de los diversos órganos de la Cooperativa, requiere que el grupo cuente con un asesoramiento técnico que le ayude a analizar los problemas, a planificar $y$ a tomar las decisiones necesarias. Esta tarea está reservada por la Ley de Vivienda a los Institutos de Asistencia Técnica, "destinados a propor- cionar al costo servicios jurídicos, de educación cooperativa, financieros, económicos y sociales, pudiendo incluir también los servicios técnicos de proyecto y dirección de obras"; todos ellos, de acuerdo a la Ley, deben ser brindados sin fines de lucro.

La Ley y su reglamentación regulan asimismo el alcance del asesoramiento que debe ser brindado, así como su remuneración máxima; el incumplimiento de esas disposiciones acarrea la pérdida de la personalidad Jurídica del Instituto y con ello la inhabilitación para actuar. El asesoramiento abarca, como se ha expresado, aspectos muy variados: legales (obtención de la personalidad jurídica, estatutos, escrituración de terrenos, contratos, gestiones, interpretaciones reglamentarias y legales), de gestión (organización cooperativa, contabilidad administración), financieros (política de inversiones, uso de recursos), constructivos (proyectos de urbanización y viviendas, presupuestación y dirección técnica de obras), sociales (capacitación de cuadros directivos y de la base cooperativa en general, práctica de la autogestión, preparación para la convivencia, actividades comunitarias).

Los Institutos de Asistencia Técnica fueron suprimidos por la Ley 14.666 de junio de 1977, que suprimió también la Dirección Nacional de Viviendas y el Instituto de Construcción de Viviendas Económicas (I.N.V.E.), y concentró la responsabilidad de la ejecución de la política de viviendas uruguaya en el Banco Hipotecario. Estas medidas se inscribieron en el marco de la política neoliberal de vivienda que se implementaba en aquellos momentos, $y$, en lo que tiene que ver concretamente con los Institutos, en el desmantelamiento de todo el sistema cooperativo, que se emprendió a partir de 1975. Se autorizó únicamente que continuara el trabajo de los Institutos hasta completar el cumplimiento de los contratos de asesoramiento a Cooperativas que estuvieran en ejecución en aquel momento. Esto originó la liquidación de la inmensa mayoría de los casi sesenta equipos técnicos interdisciplinarios que se constituyeron en los primeros años de la década del 70 para cumplir esta tarea, y que llevaron adelante la construcción de más de 7.000 viviendas por el sistema cooperativo de Ayuda Mutua y otras 3.000 por el de Ahorro Previo. El Centro Cooperativista Uruguayo, que asesoró a alrededor de la mitad de esos grupos, continúa trabajando en el campo de la vivienda en virtud de la "prórroga" antes referida, dado que aún tiene contratos en ejecución. De no derogarse la citada disposición de la Ley 14.666, sin embargo, su actuación deberá terminar en dos o tres años más.

\section{El cooperativismo de Ayuda Mutua como movimiento social y político: FUCVAM}

Prácticamente desde que existieron, las Cooperativas de Ayuda Mutua sintieron la necesidad de unirse $y$ organizarse para luchar, y percibieron la importancia de esa unión y de esa organización. Las tres Cooperativas pioneras de Salto, Fray Bentos e Isla Mala, ya habían coordinado sus esfuerzos para llevar adelante aquella 
idea que parecía una utopía; ellas mismas serán las que acudirán en 1970, junto con otras ocho Cooperativas que se habían formado en ese lapso, ya dentro de la Ley de Viviendas, para fundar en 1970, precisamente en Isla Mala, la Federación Unificadora de Cooperativas de Viviendas por Ayuda Mutua, FUCVAM. Su fundación signaba ya lo que habría de ser una historia de lucha: la " $U$ " de su sigla, que quería significar "Uruguaya", debió cambiarse por "Unificadora", porque el Gobierno no autorizó que se empleara el nombre del país en el de la Federación.

El período 1970-1973 fue de activa movilización, y a través de ella se consiguió que el cooperativismo por ayuda mutua conquistara un cometido significativo en la política de vivienda del país: adjudicaciones de terrenos, aceleración de trámites, mejoras de condiciones de créditos, son algunos de los logros que caracterizan este período, que muestra el cooperativismo unido y solidario detrás de las necesidades y problemas de todas y cada una de las cooperativas que inegraban el movimiento y figurando, también, en una primera línea en la lucha por las reivindicaciones más sentidas de los sectores populares: la ocupación, la mejora del salario, la elevación de la calidad de vida. Pero el movimiento cooperativo se fortalece asimismo internamente: su base se amplía, integrando a la gran mayoría de las Cooperativas de Ayuda Mutua existentes en el país, y al mismo tiempo profundiza y extiende su acción, cubriendo no sólo el campo gremial sino también el de los servicios. Se crea la Central de Suministros, que a través de las compras masivas de materiales para los muchos cientos de viviendas cooperativas que se estaban construyendo, logra abatir

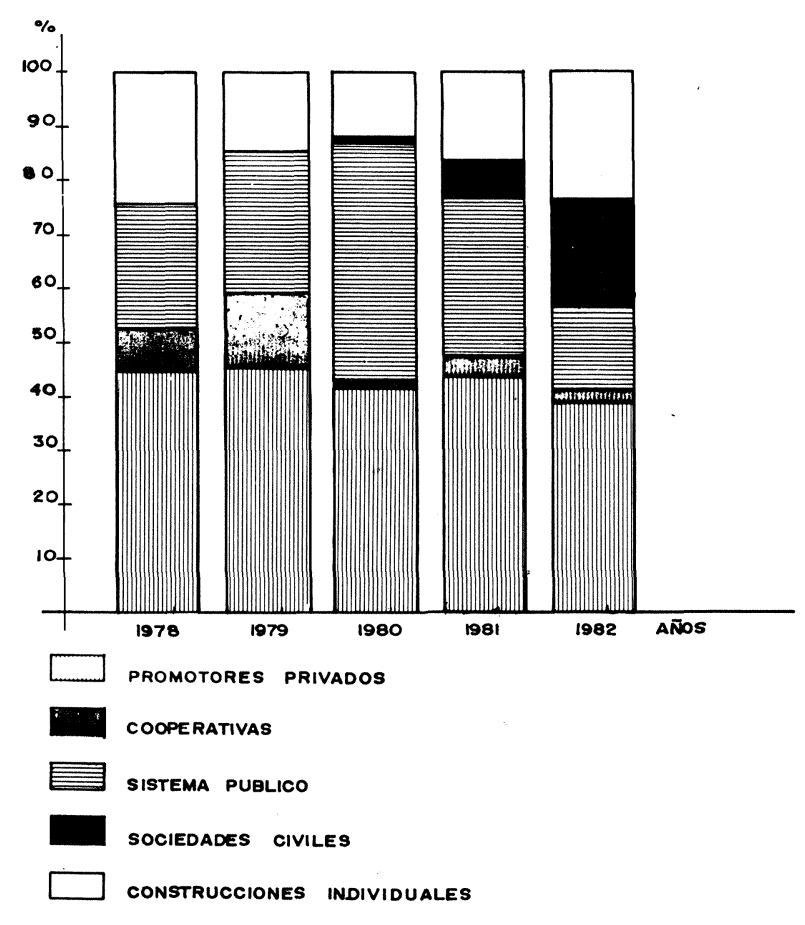

FUENTE : Memorios y Boletines Anuales BHU.

CUADRO 2. -Porcentaje de viviendas nuevas construidds pil ano, segün lineas de crédito. sensiblemente los costos y mejorar las condiciones de crédito en las adquisiciones. Se construye posteriormente una Planta de Prefabricado, con la finalidad de tecnificar y seriar la producción de ese tipo de elementos, para mejorar la calidad y reducir los costos. Este proceso se verá bruscamente detenido, sin embargo, con el cambio de la política habitacional uruguaya luego del golpe de Estado y, fundamentalmente después de 1975. Las Cooperativas son dejadas claramente de lado a partir de ese momento, privilegiándose en su lugar el apoyo a los agentes privados capitalistas (promotores, empresas). Es así que mientras el sistema de "Promoción Privada" pasa a tener el $50 \%$ de las inversiones, las Cooperativas caen por debajo del 5 \% (Cuadro 2). Pero no es sólo eso: no se otorgan nuevas personalidades jurídicas desde 1976 (lo que quiere decir que no se ha podido crear ningún nuevo grupo en ese período), y se ha retardado además enormemente la concesión de préstamos a los grupos que ya estaban formados, que deben esperar varios años para obtener su préstamo. Las condiciones de éstos, por otra parte, son mucho más duras a partir de 1979: se pasó de un interés del $2 \%$ en "unidades reajustables", a uno tres veces mayor, (lo que implica que las cuotas mensuales aumentaron un $50 \%$ ); se impuso, además, la obligación de realizar un ahorro previo.

El movimiento también fue duramente golpeado en su interior: dificultades para reunirse, para expresarse, para plantear sus problemas y reivindiaciones; dirigentes y socios destituidos o despedidos de sus empleos, muchos de ellos incluso presos; proscripción para actuar como directivos e incluso para pertenecer a las Cooperativas, de las personas con militancia sindical y política.

Todo esto afectó gravemente el movimiento cooperativo, del mismo modo que eran afectadas las demás organizaciones populares en la misma época. Pero la estructura era muy firme y las raíces muy profundas. Por eso, las bases esenciales de las organizaciones cooperativas se mantuvieron incólumes, y aún más, fueron uno de los soportes en los que se apoyó al movimiento sindical para resurgir luego de años de represión y ostracismo.

Hoy FUCVAM, que nuclea más de 120 Cooperativas y 10.000 familias, es una importante organización de masas, que junto a la Central única de trabajadores uruguaya (P.I.T.-C.N.T.), la Federación de Estudiantes (A.S.C.E.E.P.-F.E.U.U.) y las organizaciones de Derechos Humanos, representa a las llamadas "Fuerzas sociales" en la concertación con los partidos políticos democráticos del Uruguay, concertación que se lleva adelante para definir las estrategias de lucha para conseguir la democratización del país, y acordar las medidas políticas, económicas y sociales que deberán adoptarse posteriormente para rescatarlo de la grave crisis que padece en esos órdenes. $Y$ ese papel que FUCVAM asume hoy no es una casualidad: es el reconomiento a su movilización, a su lucha indeclinable, a la conciencia política de sus bases, al cometido que 
ha desempeñado en todos estos años, y particularmente en los últimos: el de organización de avanzada del movimiento popular uruguayo (Fig. 4).

\section{Dos antiguas discusiones}

Al ponerse en marcha el Cooperativismo de Vivienda en el Uruguay, se levantaron dos clásicos argumentos contra la Ayuda Mutua, que vale la pena analizar hoy, quince años después. 1. La Ayuda Mutua es un sistema que pretendiendo solucionar un problema de las clases trabajadoras - la vivienda-, trae como consecuencia, en definitiva, su sobre-explotación: terminada la jornada o la semana de labor que el trabajador realiza para atender a su subsistencia, éste deba todavía hacer un esfuerzo adicional en la Cooperativa para cubrir sus horas de Ayuda Mutua. La vivienda decorosa es un derecho de la persona humana y como tal es obligación del Estado proporcionarla, sin que deba exigirse a las familias destinatarias otro aporte que el pago que corresponde por el bien que reciben en uso o propiedad. 2. La construcción por Ayuda Mutua, al emplear mano de obra benévola, tiende a crear desocupación entre los trabajadores de la construcción, que son reemplazados por los cooperativistas, creándose así un importante problema social.

Ambos argumentos son erróneos, y los tres lustros de aplicación del sistema en el Uruguay lo han probado claramente. Comencemos por la sobreexplotación. En primer lugar la Ayuda Mutua es una solución que debe valorarse en el contexto social en el cual se emplea. En una sociedad en la cual cada familia tuviera un ingreso acorde con sus necesidades - incluida la de vivienda- podría parecer más lógico, efectivamente, sustituir el importante esfuerzo que se debe realizar durante la construcción de las viviendas por ayuda mutua, por otro tipo de acción más racional y planificada, en la que el interesado podría eventualmente contribuir con un esfuerzo complementario en su propio trabajo. Esto de todos modos podría ser discutible, porque la construcción de la vivienda con el propio esfuerzo, trabajando en la obra y tomando decisiones en conjunto, genera formas de solidaridad y capacidades organizativas que no se obtienen cuando al trabajador se le "da" la vivienda, pero en todo caso esta es una discusión para otro contexto social. En el caso uruguayo (en general, en el de los países de capitalismo dependiente), la alternativa a la ayuda mutua no es la concesión de la vivienda, sino la compra o el alquiler de la misma compra o alquiler que debe realizar en el mercado, y por los que debe pagar con un trabajo adicional en su propia ocupación o dividiendo la parte de su salario que destina a otras necesidades básicas no sólo el valor del bien que obtiene, sino también las ganancias de los intermediarios que actúan en una economía de mercado para producir ese bien (empresarios, promotores, inversionistas).

Ese trabajo adicional, además, y esto es lo fundamental, debería ser mayor que el que el trabajador tendría que hacer en la Cooperativa. Probémoslo con unas pocas cifras. Tomemos el caso del Conjunto "COVINE 5" de Montevideo, por ejemplo. El valor promedio de las viviendas resultó de $2.287,4$ UR (unidades reajustables; 1 UR equivale a 225,13 nuevos pesos y el valor del dólar americano a la fecha es de unos 56 nuevos pesos). El ahorro obtenido por la intervención de la Ayuda Mutua (en el pago de la mano de obra y leyes sociales correspondientes, en los costos de administración, en la eliminación de los beneficios de empresa), se puede calcular, en comparación con otros programas en los que la construcción se realiza por empresas, es aproximadamente 500 UR, o sea, alrededor del $22 \%$ de costo total.

Esas 500 UR son el valor económico del trabajo realizado por el cooperativista durante los 30 meses de duración de la obra, trabajando 80 horas por mes. Por consiguiente representan un ahorro de unas 0,21 UR por cada hora trabajada. Para que a ese trabajador le conviniera realizar esa hora de trabajo en su propia actividad y no en la Cooperativa, debería ganar un salario nominal mensual de $0,21 \times 8 \times 25 \times 1,17=49$ UR/mes, o sea, 3,25 salarios mínimos (el salario mínimo es de N\$3.410, o sea unas 15 UR), suponiendo 25 días de labor, 8 hs. por jornada y un $17 \%$ de descuento por Leyes Sociales.

Ahora bien: el 50 \% de la población uruguaya —el de menores ingresos, aquel que integra las Cooperativas de Ayuda Mutua-, no gana ese salario. La conclusión es clara: para los cooperativistas es más conveniente, por su nivel de ingresos, el trabajo en la obra y la auto gestión cooperativa, que pagar, con horas adicionales de trabajo en su propia ocupación, la realización de esas tareas por trabajadores contratados.

El segundo argumento es aún más fácil de rebatir: la mano de obra profesional ("contratada") utilizada por cada metro cuadrado construido, es efectivamente menor en un programa de construcción de viviendas por Ayuda Mutua que en uno que se realiza a través de empresas privadas y ello se debe a que parte de la mano de obra es realizada por los propios cooperativistas. Pero en cambio la mano de obra contratada utilizada en relación a la inversión es mayor, y aún mucho mayor, en los programas de Cooperativas de Ayuda Mutua (ver Cuadro 3) que en los demás. Y la razón para ello es muy clara: en los programas cooperativos se eliminan las ganancias de los intermediarios, que son enormes, con lo que el costo del producto final se abate sensiblemente, y se pueden construir muchas más viviendas con la misma inversión. Eso hace que en definitiva, para la misma inversión realizada se emplee más mano de obra contratada, en valores absolutos, en las Cooperativas de Ayuda Mutua que en cualquier otro tipo de programa, con el agregado, nada despreciable, de que el producto que se incorpora al patrimonio nacional en aquel caso es además mucho mayor. Las cifras del Cuadro 3, obtenidas a partir de valores reales de proyectos llevados a cabo en el Uruguay, eximen de mayores comentarios. 
CUADRO 3

COMPARACION DEL EMPLEO DE MANO DE OBRA EN PROGRAMAS REPRESENTATIVOS DE DISTINTOS SISTEMAS, CONSTRUIDOS EN MONTEVIDEO

\begin{tabular}{|c|c|c|c|c|c|c|c|}
\hline & \multirow{2}{*}{$\begin{array}{l}\text { Valor de } \\
\text { tasación } \\
\text { por } \mathrm{m}^{2} \\
\text { habitable } \\
\text { (UR) }\end{array}$} & \multirow{2}{*}{$\begin{array}{l}\text { Costo neto } \\
\text { para el } \\
\text { usuario } \\
\text { por } \mathrm{m}^{2} \\
\text { habitable } \\
\text { (UR) }\end{array}$} & \multicolumn{3}{|c|}{$\begin{array}{l}\text { Costo de mano } \\
\text { de obra contratada }\end{array}$} & \multirow{2}{*}{$\begin{array}{l}\text { Relación de } \\
\text { Costos de } \\
\text { Mano de Obra } \\
\text { Contratada } \\
\text { sobre Valor } \\
\text { de Tasación }\end{array}$} & \multirow{2}{*}{$\begin{array}{l}\text { Relación de } \\
\text { Costos de } \\
\text { Mano de Obra } \\
\text { Contratada } \\
\text { sobre costo } \\
\text { neto para el } \\
\text { usuario }\end{array}$} \\
\hline & & & UR/M2 & $\begin{array}{l}\text { \% sobre } \\
\text { valor } \\
\text { de } \\
\text { tasación }\end{array}$ & $\begin{array}{l}\% \text { sobre } \\
\text { costo neto } \\
\text { para el } \\
\text { usuario }\end{array}$ & & \\
\hline $\begin{array}{l}\text { Cooperativas } \\
\text { de Ayuda Mutua } \\
\text { categoría } \\
\text { económica }\end{array}$ & 37,08 & 33,11 & 8,96 & 24 & 27 & 1 & 1 \\
\hline $\begin{array}{l}\text { Promoción } \\
\text { Privada } \\
\text { categoría } \\
\text { media }\end{array}$ & 68,00 & 85,00 & 15,64 & 23 & 18 & 0,96 & 0,67 \\
\hline $\begin{array}{l}\text { Sociedades } \\
\text { Civiles } \\
\text { categoría } \\
\text { media }\end{array}$ & 66,61 & 66,61 & 12,43 & 19 & 19 & 0,79 & 0,70 \\
\hline
\end{tabular}

OBSERVACIONES:

1. 1 UR $=3,88$ US $\$$ (relación agosto 1984).

2. Las Sociedades Civiles son entidades sin fines de lucro, que construyen viviendas para sus asociados, las que se otorgan en régimen de propiedad horizontal. La construcción se realiza por empresas privadas, aunque no siempre por licitación. Este sistema ha presentado serios inconvenientes porque las Sociedades no siempre son "genuinas", sino que a veces se trata de programas promovidos por intermediarios privados con fines especulativos.

3. Valor de Tasación: Avalación del costo del programa según el Banco Hipotecario del Uruguay, incluyendo terreno, obras de infraestructura, conexiones de servicios y honorarios profesionales, y en el caso de las Cooperativas de Ayuda Mutua, estimación del valor de la mano de obra benévola utilizada. No incluye ganancia del Promotor Privado para ese tipo de programa.

4. Costo neto para el usuario: Igual al Valor de Tasación, salvo para las Cooperativas de Ayuda Mutua, en que se resta la mano de obra benévola, y los programas de Promoción Privada, en que se suma la ganancia del Promotor.

\section{Por qué Cooperativas de Ayuda Mutua}

¿Construcción por inversores privados, a través del Estado, o por Cooperativas? Esta pregunta seguramente no tiene una sola respuesta; en efecto, mal podría pensarse, por ejemplo, que la única vía de construcción de viviendas con financiamiento público fueran las Cooperativas, descartando toda otra alternativa. Lo que sí puede afirmarse, luego de evaluar la experiencia de más de 15 años de cooperativismo de vivienda por Ayuda Mutua en el Uruguay, es que este sistema debería tener una participación destacada en la solución de los problemas habitacionales. Las razones de esta afirmación estriban en las importantes ventajas comparativas que el cooperativismo ha demostrado tener desde muchos puntos de vista a lo largo de ese período. Repasémoslas rápidamente.

\section{Desde el punto de vista social:}

- Las experiencias de Cooperativas de Vivienda por Ayuda Mutua están indisolublemente ligadas a la autogestión y participación, así como la aplicación de los principales cooperativos fundamentales (en la organización, en el trabajo, en la convivencia) llevan a que se trasmitan y profundicen valores de solidaridad, de democracia, de respeto mutuo, que son diferentes $y$ hasta opuestos a los de individualismo y competencia que predominan actualmente en nuestra sociedad. La realización de ayuda mutua, en cuanto, implica el esfuerzo mancomunado de todas las familias destinatarias, y no sólo de aquéllos que actúan como dirigentes del grupo, es un factor fundamental en la consolidación de esos valores. Es por ello que aún cuando se pueda obviar la realización de ayuda mutua 
como una necesidad económica para abatir los costos de la viviendas, resulta importante mantenerla de alguna forma para alcanzar los objetivos citados.

- La capacidad de cooperación y autoayuda alcanzada, por otra parte, se traslada luego a la solución de otras necesidades familiares y comunales, a través de la propia Cooperativa o de otras formas de organización popular. Así las Cooperativas han propiciado, por su propia acción o estimulando la intervención del Estado y de la comunidad, la solución de los problemas más variados:

* Obtención de servicios esenciales: de infraestructura (agua, saneamiento, energía eléctrica, recolección de servicios domiciliarios, transporte), culturales (jardines de niños, guarderías, escuelas primarias, educación física, biblitoecas, actividades artísticas), de salud (policlínicas, asistencia preventiva, asistencia odontológica), de alimentación (comidas populares, cooperativas de consumo), etcétera.

* Solidaridad hacia las familias con dificultades económicas o sociales (desempleados, sub-ocupados, y en este período también destituidos, perseguidos y presos por razones políticas).

- El funcionamiento de la Cooperativa como empresa social y económica exige de sus integrantes un esfuerzo permanente de capacitación, desde la etapa organizativa hasta la de obra, así como en la etapa posterior y definitiva, que es la de mantener la comunidad cooperativa luego de construidas las viviendas. Esa exigencia de capacitación e integración de conocimientos y experiencias actúa como una verdadera escuela de educación asistemática, y sus efectos trascienden a la Cooperativa y se trasladan a la familia y a la comunidad circundante.

\section{Desde el punto de vista de la utilización de los recursos disponibles:}

- En primer lugar, el control del desarrollo de los programas por quienes mayor interés tienen en su éxito y eficacia, los propios destinatarios, hace que se alcance un nivel de eficiencia muy sifnificativo sin necesidad de recurrir a los mecanismos a que apelan para obtener ese fin las empresas capitalistas.

- La construcción y administración de las viviendas por la Cooperativa, eliminando a los intermediarios y sustituyendo en buena parte la acción de la propia administración pública, alivia a ésta de una tarea muy ardúa en la ejecución y control de los programas.

- En lo que se refiere a las inversiones a realizar, éstas son menores en las Cooperativas de Ayuda Mutua que en otros sistemas, porque:

* Se ahorra entre un 10 y un $15 \%$ del costo total, que se realiza por Ayuda Mutua.
* Se eliminan los intermediarios y con ello sus ganancias: las de la empresa constructora, (que son del orden del $15 \%$ sobre el costo de construcción) y en buena medida, también la de las empresas sub-contratistas; las de los promotores privados, que normalmente tienen un beneficio de aproximadamente el $25 \%$ sobre el costo total del programa; se ahorra, en fin, el beneficio que obtienen las inmobiliarias encargadas de la venta de las unidades, que es del $3 \%$ sobre el costo de la vivienda, cantidad que debe pagar el adquirente.

Importa señalar que a pesar de que los grandes conjuntos del Sistema Público pueden obtener mejores costos relativos debido a la economías de escala (a costa de otros valores muy importantes que estos conjuntos dejan de lado), esas economías no se traducen de todos modos en un costo final más bajo, ya que son absorbidas por los beneficios de las empresas actuantes.

- En cuanto al costo para el usuario - que debe incluir en el caso de las Cooperativas de Ayuda Mutua el valor económico de su contribución en trabajo-, ésta es similar al de las obras realizadas por administración directa por el Estado, a igualdad de producto terminado y a igualdad de condiciones financieras (ver Cuadro 4).

- Asimismo los costos de mantenimiento se reducen en un programa cooperativo de Ayuda Mutua, ya que al haber participado los socios en la construcción del conjunto, están en mejores condiciones que en cualquier otro sistema para encarar el mantenimiento (Fig. 4). Esto se extiende también a las complementaciones posteriores, tanto de las viviendas como del equipamiento comunitario y urbano.

\section{Desde el punto de vista del diseño:}

- Mejor adaptación de lo construido a las necesidades de los destinatarios. El control de la experiencia por los propios usuarios hace que esto sea posible ya que tienen la posibilidad de elegir desde el terreno (en una ubicación que les resulte adecuada), hasta el tipo de vivienda y servicios complementarios a construir (Fig. 5). Además, por el hecho de conformarse primero el grupo cooperativo y luego encararse el proyecto de acuerdo a las necesidades del mismo, el sistema se adapta adecuadamente tanto a las ciudades grandes como a las pequeñas poblaciones del interior del país, donde raramente se construyen programas de "interés social" por parte del Estado y donde los inversionistas privados no llegan porque las tasas de rentabilidad son bajas o no existen.

- Valorización del espacio comunitario: en forma gradual los usuarios de los conjuntos han ido integrando los espacios comunes (sendas, calles, plazas). $\mathrm{Su}$ aportaciones a la complementación del equipamiento urbano, sumadas a las realizadas en las zonas frontales de uso privado, van estableciendo sectores caracterizados y referencias de ubicación que en- 
CUADRO 4

COSTOS FINALES PARA LOS USUARIOS DE PROGRAMAS REPRESENTATIVOS DE DISTINTOS SISTEMAS CONSTRUIDOS EN MONTEVIDEO

\begin{tabular}{|c|c|c|}
\hline Programa & $\begin{array}{l}\text { Costo por } m^{2} \\
\text { Habitable en UR } \\
\text { (1 UR = U\$S } 3,88)\end{array}$ & Observaciones \\
\hline $\begin{array}{l}\text { Ayuda Mutua } \\
\text { Covine } 5\end{array}$ & $35,17 \mathrm{UR} / \mathrm{m}^{2}$ & $\begin{array}{l}\text { Costo final, incluye Ayuda mutua. } 200 \text { viviendas duplex, salón } \\
\text { comunal y guardería para niños. }\end{array}$ \\
\hline Covicenova & $38,99 \mathrm{UR} / \mathrm{m}^{2}$ & $\begin{array}{l}\text { Costo final, incluye Ayuda mutua. } 102 \text { viviendas de un ivel, } \\
\text { salón comunal y guardería para niños. }\end{array}$ \\
\hline $\begin{array}{l}\text { Fondo Social } \\
\text { Cutcsa } 4\end{array}$ & $39,18 \mathrm{UR} / \mathrm{m}^{2}$ & $\begin{array}{l}\text { Costo en base a precios de licitación. } 118 \text { viviendas en } \\
\text { bloques de } 4 \text { niveles de altura y salón comunal. }\end{array}$ \\
\hline $\begin{array}{l}\text { Sociedades Civiles } \\
\text { Atahualpa } \\
\text { Lapido }\end{array}$ & $\begin{array}{l}51,72 \cup R / m^{2} \\
66,61 \mathrm{UR} / \mathrm{m}^{2}\end{array}$ & $\begin{array}{l}\text { Costo inal. } 40 \text { viviendas duplex y salón comunal. } \\
\text { Costo final, } 36 \text { viviendas y salón comunal. Edificio en torre. }\end{array}$ \\
\hline $\begin{array}{l}\text { Promoción Privada } \\
\text { Parque del Sol } \\
\text { Verdysol } \\
\text { Varios } \\
\end{array}$ & $\begin{array}{l}75,00 \cup R / m^{2} \\
57,98 \cup R / m^{2} \\
85,00 \cup R / m^{2}\end{array}$ & $\begin{array}{l}\text { Precio de venta - Bloques de } 4 \text { niveles. } \\
\text { Precio de venta - Bloques de } 4 \text { niveles. } \\
\text { Precio de venta - Edificios en altura. }\end{array}$ \\
\hline $\begin{array}{l}\text { Sistema Público } \\
\text { Conjunto América }\end{array}$ & $35,14 \mathrm{UR} / \mathrm{m}^{2}$ & $\begin{array}{l}\text { Precio de licitación - No incluye el terreno ni costos operativos } \\
\text { del Banco. } 1150 \text { viviendas en edificios en torre. }\end{array}$ \\
\hline $\begin{array}{l}\text { Conjunto } \\
\text { Euskal Erría }\end{array}$ & $39,25 \mathrm{UR} / \mathrm{m}^{2}$ & idem - 3.000 viviendas. \\
\hline
\end{tabular}

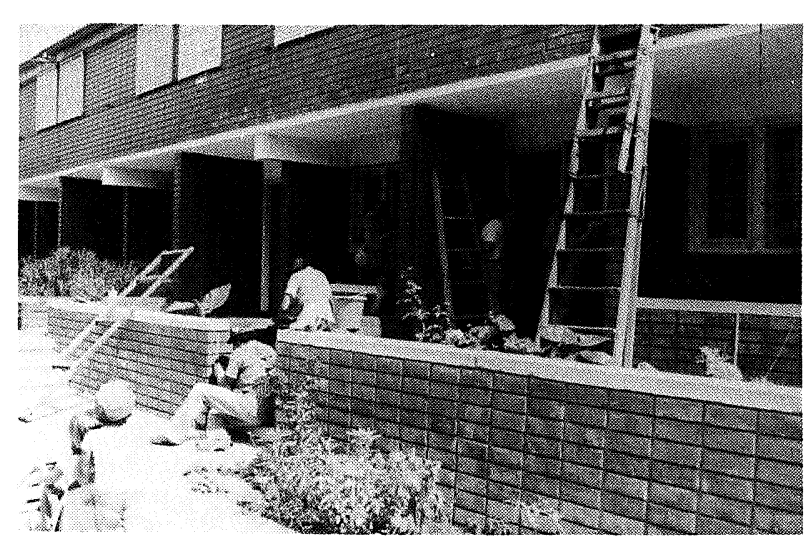

Fig. 4. - Terminada la obra, el esfuerzo se vuelca al mantenimiento, asicomoal mejoramiento de las viviendas y el entorno.

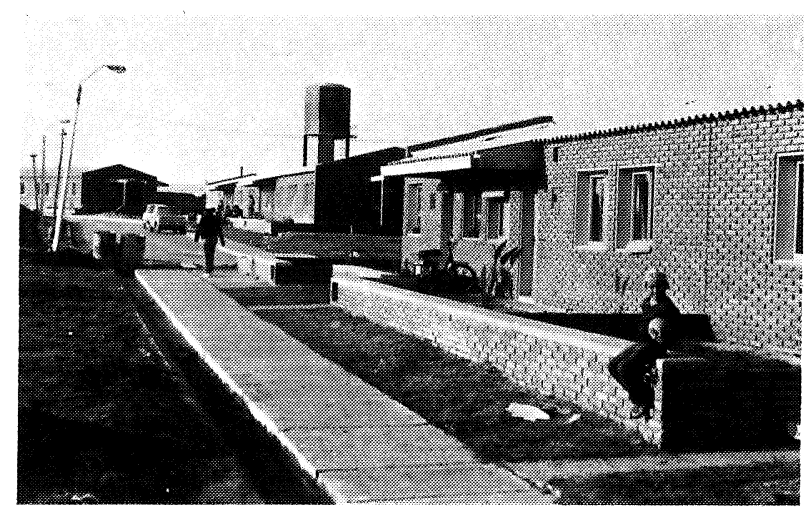

Fig. 5. - COVICENOVA, proyecto de 102 viviendas populares en e/suburbio montevideano: casas de un nivel, con espacios privados al fren te y al fondo, de acuerdo a las tipologias comunes en la zona y a las necesidades de los usuarios.

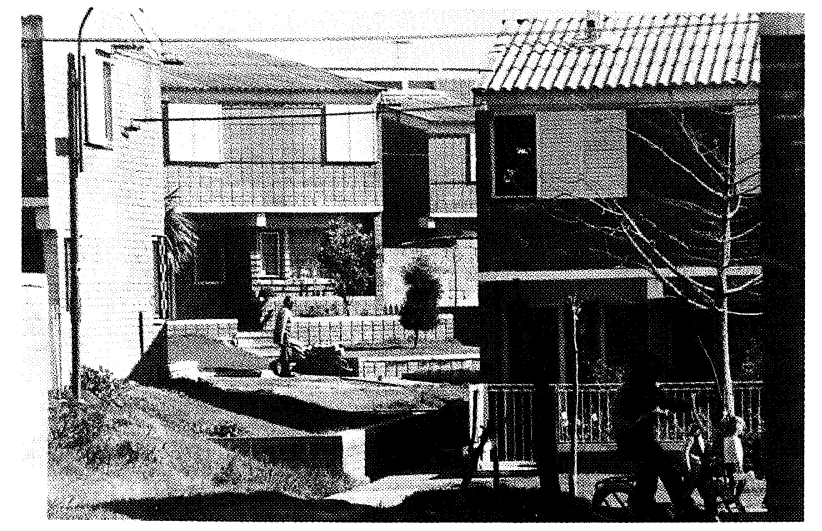

Fig. 6. - Los usuarios actúan sobre los espacioes comunes y scbre las zonas frontales de uso privado de los conjuntos cooperativos, estableciendo sectores caracterizados y referencias de ubicación que enriquecen la imagen urbana de los conjuntos.

riquecen la imagen urbana de los conjuntos (Fig. 6). EI cuidado de estos espacios es muy superior, por otra parte, al de los barrios de formación espontánea en los que los conjuros cooperativos se insertan.

\section{9. ¿Una alternativa latinoamericana?}

Las Cooperativas de Ayuda Mutua uruguayas recogen, como hemos dicho, un conjunto de tradiciones, a las que recrean para darles nuevas formas y contenidos: las de las Cooperativas como forma organizativa, las de los autoconstructores, las de los movimientos populares de los que provienen sus integrantes, que traen de ellos sus experiencias de organización y de lucha. Esas 
tradiciones, esas viviencias, son las que se unen para forjar lo que hoy es el cooperativismo de ayuda mutua: un método para construir viviendas populares, en un principio, que deviene en una forma de organización y en una concepción de la sociedad en función de valores de justicia, de fraternidad y de solidaridad.

Este resultado sin duda está indeleblemente marcado por las características propias de la sociedad que lo produjo. El "mcide" seguramente no se ajusta a otras realidades, a otros contextos sociales e históricos, ni aún de los países de Latinoamérica, por más que haya muchos rasgos característicos comunes y por más que en definitiva también sea común el origen de los problemas y los caminos para enfrentarlos. Sin embargo, la idea básica, que es la de la búsqueda de soluciones a través de la autogestión popular, aparece como necesariamente vinculada a toda experiencia que pretenda avanzar realmente en la resolución de los problemas de la vivienda y el habitat de las grandes mayorías de nuestras poblaciones. Por ello la experiencia del cooperativismo de Ayuda Mutua uruguayo bien puede servir de referencia a otros intentos que se realicen en los países de Latinoamérica y en general en los países de periferia.

Esto ya está sucediendo, en los hechos, a través de la difusión que esa experiencia ha podido tener en Encuentros de vivienda, Congresos, publicaciones, e incluso -y quizá más aún- por su transmisión directa por sus propios protagonistas - usuarios y técnicos-, a quienes la crisis social, económica y política de la última década en el Uruguay ha dispersado por el mundo. Así, hoy se llevan adelante intentos que toman muchos aspectos de las realizaciones del cooperativismo de ayuda mutua uruguayo, en Brasil, en Colombia, en Méjico, y se procura implantarlos en Argentina. Si este artículo logra tránsmitir los valores y las posibilidades de la experiencia en que nos ha tocado participar, y con ello proporciona elementos de apoyo a quienes están trabajando en el mismo sentido en otros países de Latinoamérica en el área de la vivienda popular, habrá cumplido plenamente su objetivo.

\section{Referencias}

1. TERRA, J. P., 1969. "La Vivienda". Colección "Nuestra Tierra", n.o 38. Editorial "Nuestra Tierra", Montevideo.

2. MELGAR, A., y CANCELA, W., 1983. "Economía: La hora del balance". Colección "El Uruguay de Nuestro Tiempo", n. ${ }^{\circ} 1$. Publicación del Centro Latinoamericano de Economía Humana (CLAEH), Montevideo.

3. TERRA, J. P., op. cit.

\section{Bibliografía sumaria}

1. "El Cooperativismo de Ayuda Mutua en el Uruguay: La experiencia del Centro Cooperativista Uruguayo", ponencia presentada por el Centro Cooperativista Uruguayo en el Encuentro sobre Vivienda Popular del Cono Sur. Montevideo, mayo de 1984.

2. "Cinco años de Política neoliberal de vivienda en el Uruguay: 1977. 1982", ponencia presentada por el Centro Cooperativista Uruguayo en el Segundo Congreso Nacional de la Sociedad de Arquitectos del Uruguay. Montevideo, noviembre de 1983.

3. Ley Nacional de Viviendas (Ley 13.728 del 17 de diciembre de 1968), publicación del Diaro Oficial de la República Oriental del Uruguay, 27 de diciembre de 1968.

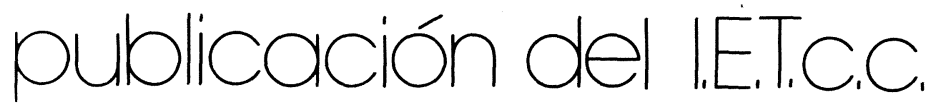

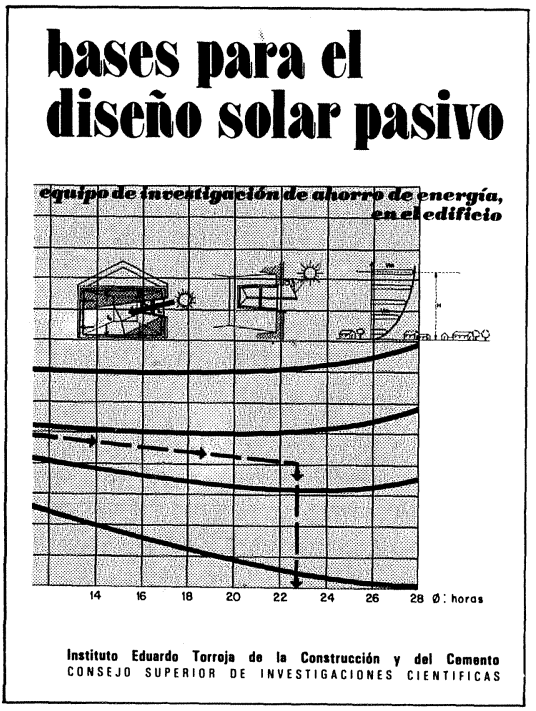

Equipo de Ahorro de Energía en el edificio

Dirección y coordinación: Arturo García Arroyo

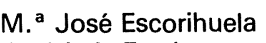

José Luis Esteban

José Miguel Frutos

Manuel Olaya

Bernardo Torroja arquitectónico solar, al margen de las condiciones climáticas y funcionales específicas de cada caso y lugar.

En este libro, utilizando criterios y metodología pedagógicos, se dan los fundamentos e instrumentos teórico-prácticos necesarios para el planteamiento de todo proyecto arquitectónico solar pasivo, de acuerdo con los principios éticos y económicos de conservación y ahorro de energia. Es decir: respeto de los presupuestos bioclimáticos, búsqueda de la máxima captación y acumulación de la radiación solar, y esmero en el aislamiento térmico de los cerramientos.

Un volumen encuadernado en cartulina ibiza plastificada, a cinco colores, de $16 \times 23 \mathrm{~cm}$, compuesto de 216 páginas, 217 figuras, 87 gráficos, 19 tablas y 10 cuadros.

Madrid, 1983. Precios: España 2.100 ptas.; 30 \$ USA. 